\title{
Wind Energy System MVA Profile Enhancement based on Feedback Quadratic Function Controller
}

\author{
Firas M. Tuaimah \\ University of Baghdad \\ College of Engineering \\ Electrical Department
}

\begin{abstract}
With the increase in the wind turbine power and size, its control system plays an important role to operate it in safe region and also to improve energy conversion efficiency and output power quality. In this paper a feedback quadratic function controller for controlling a wind energy system is presented. A nonlinear wind energy system has been linearized and simulated using MATLAB programming language. An enhanced profile has been acquired for active and reactive power when adopting the feedback quadratic controller, through checking the settling time of the step response.
\end{abstract}

\section{Keywords}

Wind Energy, quadratic Function, and feedback controller.

\section{INTRODUCTION}

Wind energy is the most promising renewable source of electrical power generation for the future. Many countries promote the wind power technology through various national programs and market incentives. Wind energy technology has evolved rapidly over the past three decades with increasing rotor diameters and the use of sophisticated power electronics to allow operation at variable speed [1].

Wind energy can be harnessed by a wind energy conversion system, composed of wind turbine blades, an electric generator, a power electronic converter and the corresponding control system. There are different WECS configurations based on using synchronous or asynchronous machines, and stall-regulated or pitch regulated systems. However, the functional objective of these systems is the same: converting the wind kinetic energy into electric power and injecting this electric power into a utility grid.

[1] Proposed a nonlinear controller for a variable speed device to produce electrical energy on a power network, based on a doubly - fed induction generator (DFIG) used in wind energy conversion systems, two types of controllers: adaptive fuzzy logic and sliding mode. Their respective performances are compared in terms of power reference tracking, response to sudden speed variations, sensitivity to perturbations and robustness against machine parameters variation.

[2] proposed A new method for obtaining the maximum power output of a doubly - fed induction generator (DFIG) wind turbine to control the rotor and grid - side converter, a control technique based on the Lyapunov function are adopted, the simulation results shows that when the proposed method is used, the wind turbine is capable of properly tracking the optimal operation point.
[3] Presented a complete - order modeling of state - space representations of synchronous and induction generators for wind turbine applications. Fully equivalent models with different state variables, suitable for different control schemes, are given. Simulation results of the featured representations are assessed.

[4]Presented the modeling of variable speed wind turbines for stability studies, suitable control algorithms for the simulation of the doubly-fed induction machine (DFIM) as well as the permanent magnet synchronous machine (PMSM), The control schemes include the pitch-angle/speed control and the decoupled control of the real and reactive power outputs.

[5] Presented the Mathematical modeling of synchronous and induction generators for wind turbines using state space. Equivalent models with different state variables, suitable for different control schemes, are given. The performance of fixed and variable - speed wind turbines under faults and voltage sags is assessed.

[6] Presents a new artificial intelligence-based detection method of open switch faults in power converters connecting doubly-fed induction (DFIG) generator wind turbine systems to the grid. In order to improve the performance of the closed - loop system during transients and faulty conditions, current control is based on a PI (proportional - integral) controller optimized using genetic algorithms. The simulation model was developed in Matlab/Simulink environment and the simulation results demonstrate the effectiveness of the proposed FTC method and closed - loop current control scheme.

[7] Presents a distributed model predictive control (DMPC) based on coordination scheme. The proposed algorithm solves a series of local optimization problems to minimize a performance objective for each control area. The generation rate constraints (GRCs), load disturbance changes, and the wind speed constraints are considered. Furthermore, the DMPC algorithm may reduce the impact of the randomness and intermittence of wind turbine effectively. A performance comparison between the proposed controller with and without the participation of the wind turbines is carried out. Analysis and simulation results show possible improvements on closed-loop performance, and computational burden with the physical constraints.

\section{THE PROPOSED WIND TURBINE SYSTEM}

The basic components involved in the representation of a typical wind turbine generator are shown in Figure 1. 


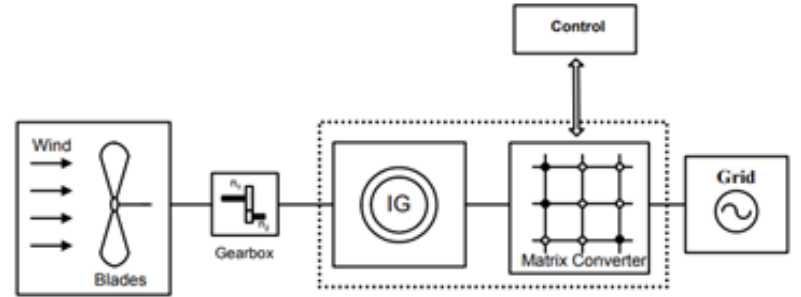

Fig 1: Schematic diagram of the wind turbine system

The figure shows model blocks for wind speed, the aerodynamic wind turbine, mechanical components, electrical generator, matrix converter, and utility grid. The system may also contain some mechanical parts for blades angle control.

MC interfaces the induction generator with the grid and implements a shaft speed control methods to achieve maximum power-point tracking at varying wind velocities. It also performs power factor control at the grid interface and satisfies the Var demand at the induction generator terminals. [8]

\subsection{Common Generator Types in Wind Turbines}

The function of an electrical generator is providing a means for energy conversion between the mechanical torque from the wind rotor turbine, as the prime mover, and the local load or the electric grid. Different types of generators are being used with wind turbines. Small wind turbines are equipped with DC generators of up to a few kilowatts in capacity. Modern wind turbine systems use three phase AC generators [8 and 9]. The common types of AC generator that are possible candidates in modern wind turbine systems are as follows:

- $\quad$ Squirrel - Cage (SC) rotor Induction Generator (IG),

- Wound - Rotor (WR) Induction Generator,

- Doubly - Fed Induction Generator (DFIG),

- Synchronous Generator (With external field excitation), and

- Permanent Magnet (PM) Synchronous Generator

\subsection{Matrix Converter (MC)}

Matrix converter (MC) is a one - stage $\mathrm{AC} / \mathrm{AC}$ converter that is composed of an array of nine bidirectional semiconductor switches, connecting each phase of the input to each phase of the output. This structure is shown in Figure 2. The basic idea behind matrix converter is that a desired output frequency, output voltage and input displacement angle can be obtained by properly operating the switches that connect the output terminals of the converter to its input terminals. In this method, known as direct method, the output voltages are obtained from multiplication of the modulation transfer matrix by input voltages. Since then, the research on the MC has concentrated on implementation of bidirectional switches, as well as modulation techniques.

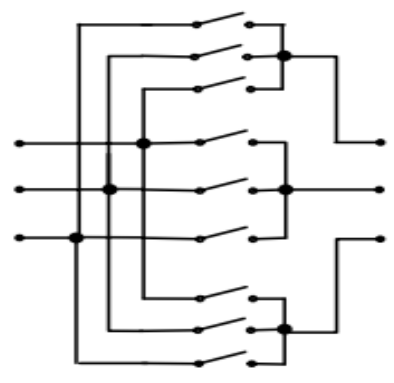

Fig 2: Matrix converter structure

One of practical problems in the implementation of MC is the use of four-quadrant bidirectional switches. Using this type of switch is necessary for successful operation of MC [8].

\section{CONTROL METHODS}

With the evolution of WECS during the last decade, many different control methods have been developed. The control methods developed for WECS are usually divided into the following two major categories:

- Constant - speed methods, and

- Variable - speed methods.

\subsection{Variable - Speed turbine Versus Constant-Speed Turbine}

In constant - speed turbines, there is no control on the turbine shaft speed. Constant speed control is an easy and low - cost method, but variable speed brings the following advantages:

- Maximum power tracking for harnessing the highest possible energy from the wind,

- Lower mechanical stress,

- Less variations in electrical power, and

- Reduced acoustical noise at lower wind speeds.

\section{DYNAMIC MODEL OF THE WIND TURBINE SYSTEM}

The components of the wind turbine system, shown in Figure 3 below, will be modeled by thirteen nonlinear equations (excluding the wind model): three, equations for the wind turbine and shafts; six for the MC in balanced three-phase operation; and four, for the induction machine. Using these equations, a complete dynamic model of the wind turbine will be developed in this section. In the proposed system of Figure 1, the input and output sub-circuits of the MC are connected to the electrical grid and the stator terminals of the induction generator, respectively. Therefore, the following equations can be written for the voltages, currents and frequency of the $\mathrm{MC}$, as well as the induction generator terminal voltages [8]:

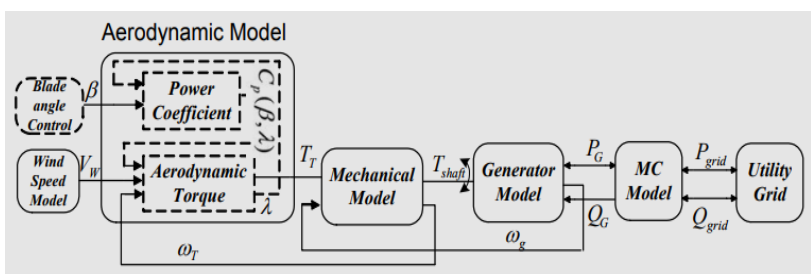

Fig 3: block diagram of wind turbine system model 
Generator terminal voltages:

$v_{q s}=v_{q_{-} \text {out }}, v_{q s}=v_{q_{\text {out }}}$

Generator terminal currents:

$i_{q s}=i_{q o}, i_{d s}=i_{d o}$

Generator synchronous frequency and MC input frequency:

$\omega_{\mathrm{o}}=\omega_{e}, \omega_{i}=\omega_{\text {Grid }}$

MC input sub-circuit terminal voltages:

$v_{q G}=v_{q_{-} i n}, v_{d G}=v_{d_{-} i n}$

The generator terminal voltages, $v_{\mathrm{qs}}$ and $v_{\mathrm{ds}}$, should be stated in terms of state variables and inputs variables. Note that, for the overall system, the grid voltage, $v_{\mathrm{qG}}$ and $v_{\mathrm{dG}}$, are the input variables.

The generator voltage can be written as follows:

$$
\begin{aligned}
& v_{q s}=v_{q_{-} \text {out }}=-L_{o} \frac{d}{d t} i_{q s}-R_{o} i_{q s}-L_{o} \omega_{e} i_{d s}+v_{q o} \\
& v_{d s}=v_{d_{-} \text {out }}=-L_{o} \frac{d}{d t} i_{d s}-R_{o} i_{d s}+L_{o} \omega_{e} i_{q s}+v_{d o}
\end{aligned}
$$

The generator terminal voltages can be expressed as a function of the system state variables, as follows:

$v_{q s}=\frac{d}{d t}\left(\psi_{q s}\right) \frac{-L_{O}}{x_{l s}}\left[1-\frac{x_{m l}^{\prime}}{x_{l s}}\right]+\psi_{q s}\left(C_{3} \frac{L_{O}}{x_{l s}} \frac{x_{m l}^{\prime}}{x_{l s}}-\frac{R_{O}}{x_{l s}}\left[1-\frac{x_{m l}^{\dot{m}}}{x_{l s}}\right]\right)-\psi_{d s} \frac{L_{O} \omega_{e}}{x_{l s}}\left[1-\frac{x_{m l}^{\dot{m}}}{x_{l s}}\right]$

$$
+\psi_{q r} \frac{x_{m l}}{x_{l s}}\left(C_{4} \frac{L_{O}}{x_{l s}}+\frac{R_{O}}{x_{l s}}\right)+\psi_{d r} \frac{L_{O}}{x_{l s}} \frac{x_{m l}}{x_{l s}} \omega_{r e}+v_{q o},
$$

$v_{d s}=\frac{d}{d t}\left(\psi_{d s}\right) \frac{-L_{O}}{x_{l s}}\left[1-\frac{x_{\dot{m}}}{x_{l s}}\right]+\psi_{q s}\left(\frac{L_{O} \omega_{e}}{x_{l s}}\left[1-\frac{x_{\dot{m}}}{x_{l s}}\right]\right)-\psi_{d s}\left(\frac{L_{O}}{x_{l s}} \frac{x_{\dot{m}}}{x_{l s}} C_{3}-\frac{R_{O}}{x_{l s}}\left[1-\frac{x_{\dot{m}}}{x_{l s}}\right]\right)$

$$
-\psi_{q r} \frac{L_{O}}{x_{l s}} \frac{x_{m l}}{x_{l s}} \omega_{r e}+\psi_{d r} \frac{x_{m l}}{x_{l s} x_{l s}}\left(L_{O} C_{4}+R_{O}\right)+v_{d o},
$$

Next, using equations (7) and (8), the stator flux linkage equations, can be presented as a function of system state variables, as follows:

$$
\begin{aligned}
& \frac{d}{d t} \psi_{q s}=\dot{C}_{1} \psi_{q s}-\dot{C}_{2} \omega_{e} \psi_{d s}+\dot{C}_{3} \psi_{q r}+\dot{C}_{4} \psi_{d r} \omega_{r e}+\dot{C}_{5} v_{q o} \\
& \frac{d}{d t} \psi_{d s}=-\dot{C}_{2} \omega_{e} \psi_{q s}+\dot{C}_{1} \psi_{d s}-\dot{C}_{4} \psi_{q r} \omega_{r e}+\dot{C}_{3} \psi_{d r}+\dot{C}_{5} v_{d o}
\end{aligned}
$$

Where,

$$
\begin{gathered}
C_{o}=\omega_{b} \frac{L_{O}}{x_{l s}}\left[1-\frac{x_{m l}}{x_{l s}}\right]+1, \\
\dot{C_{1}}=\frac{1}{C_{o}}\left(C_{1}+C_{3} \frac{\omega_{b} L_{o}}{x_{l s}} \frac{x_{m l}^{\cdot}}{x_{l s}}-\frac{\omega_{b} R_{O}}{x_{l s}}\left[1-\frac{x_{m l}^{\cdot}}{x_{l s}}\right]\right), \\
\dot{C}_{2}=\frac{1}{C_{o}}\left(-1-\frac{\omega_{b} L_{o}}{x_{l s}}\left[1-\frac{x_{m l}}{x_{l s}}\right]\right), \\
\dot{C_{3}}=\frac{1}{C_{o}}\left(C_{2}+\frac{\omega_{b} x_{m l}}{x_{l s}}\left(C_{4} \frac{L_{O}}{x_{l s}}+\frac{R_{O}}{x_{l s}}\right)\right), \\
\dot{C}_{4}=\frac{1}{C_{o}} \frac{\omega_{b} L_{O}}{x_{l s}} \frac{x_{m l}}{x_{l s}}, \dot{C}_{5}=\frac{1}{C_{o}}
\end{gathered}
$$

Finally, by combining the state-equation of the mechanical shaft, electrical generator, and the MC, the overall model of the system can be described by the following eleven nonlinear equations.

$$
\begin{gathered}
\frac{d}{d t} i_{q G}^{D}=-\frac{R_{i}}{L_{i}} i_{q G}^{D}-\frac{\omega_{\text {grid }}}{2 a-1} i_{d G}^{D}-\frac{1}{L_{i}} v_{q o}+\frac{1}{L_{i}} v_{q G}^{D} \\
\frac{d}{d t} i_{d G}^{D}=\omega_{\text {grid }}(2 a-1) i_{q G}^{D}-\frac{R_{i}}{L_{i}} i_{d G}^{D}-\frac{1}{L_{i}} v_{d o}+\frac{1}{L_{i}} v_{d G}^{D} \\
\frac{d}{d t} v_{q o}=A_{7} \varphi_{q s}+A_{7}^{\prime} \varphi_{d s}+A_{8} \varphi_{q r}+A_{8}^{\prime} \varphi_{d r}+\frac{1}{c} i_{q G}^{D}-\frac{\omega_{g r i d}}{2 a-1} v_{d o}(13) \\
\frac{d}{d t} v_{d o}=A_{7}^{\prime}(2 a-1)^{2} \varphi_{q s}+A_{7}(2 a-1)^{2} \varphi_{d s}+A_{8}^{\prime}(2 a-1)^{2} \varphi_{q r}+A_{8}(2 a \\
\quad-1)^{2} \varphi_{d r}+\frac{1}{c} i_{d G}^{D}+\omega_{g r i d}(2 a-1) v_{q o} \\
\frac{d}{d t} \psi_{q s}=\dot{C}_{1} \psi_{q s}+\dot{C}_{2} \omega_{e} \psi_{d s}+\dot{C}_{3} \psi_{q r}+\dot{C}_{4} \psi_{d r} \omega_{g}+C_{5} \omega_{e} v_{q o} \\
\frac{d}{d t} \psi_{d s}=-\dot{C}_{2} \omega_{e} \psi_{q s}+\dot{C}_{1} \psi_{d s}-\dot{C}_{4} \psi_{q r} \omega_{g}+\dot{C}_{3} \psi_{d r}+\dot{C}_{5} \omega_{e} v_{d o}
\end{gathered}
$$

$$
\begin{aligned}
& \frac{d}{d t} \psi_{q r}=C_{3} \psi_{q s}+C_{4} \psi_{q r}-\left(\omega_{e}-\omega_{g}\right) \psi_{d r} \\
& \frac{d}{d t} \psi_{d r}=C_{3} \psi_{d s}+\left(\omega_{e}-\omega_{g}\right) \psi_{q r}-C_{4} \psi_{d r} \\
& \frac{d}{d t} \omega_{G}=\frac{1}{J_{G}}\left[\frac{1}{n_{\text {gear }}}\left(K_{s} \Delta \theta+B\left(\omega_{T}-\frac{2 \omega_{g}}{P n_{\text {gear }}}\right)-C_{5}\left(\psi_{d r} \psi_{q s}-\psi_{q r} \psi_{d s}\right)\right]\right. \\
& \frac{d}{d t} \theta=\omega_{T}-\frac{2 \omega_{g}}{P n_{\text {gear }}} \\
& \frac{d}{d t} \omega_{G}=\frac{1}{J_{T}}\left[\frac{1}{2 \omega_{T}} \rho A_{r} C_{p}(\beta, \lambda) V_{w}^{3}-\left(K_{s} \Delta \theta+B\left(\omega_{T}-\frac{2 \omega_{g}}{P P_{G}}\right)\right]\right.
\end{aligned}
$$

The power exchanged between grid and the wind turbine is an important quantity of the wind turbine system. Therefore, the grid active and reactive powers injected into the grid are chosen as the output variables for the model.

$$
\begin{aligned}
& P_{\text {Grid }}=\frac{3}{2 q} V_{G m}\left[\cos \left(\alpha_{o}\right) i_{d G}^{D}-\sin \left(\alpha_{o}\right) i_{d G}^{D}\right], \\
& Q_{\text {Grid }}=\frac{3}{2 q} \frac{V_{G m}}{2 a-1}\left[\sin \left(\alpha_{o}\right) i_{q G}^{D}+\cos \left(\alpha_{o}\right) i_{d G}^{D}\right]
\end{aligned}
$$

Where $\mathrm{V}_{\mathrm{Gm}}$ is the peak value of the grid phase voltage.

The schematic diagram of the wind turbine system's overall dynamic model is shown in Figure 4. The model is characterized by six inputs (u), two outputs $(\mathbf{y})$, and eleven state variables $(\mathbf{x})$. Out of the six inputs, $\omega_{\mathrm{e}}, \mathrm{q}$, a, and $\alpha_{\mathrm{o}}$ are adjustable control variables of the MC, $\beta$ is pitch angle of the turbine blades, and VW is the wind velocity. The active and reactive powers injected into the grid are treated as output variables for the model.

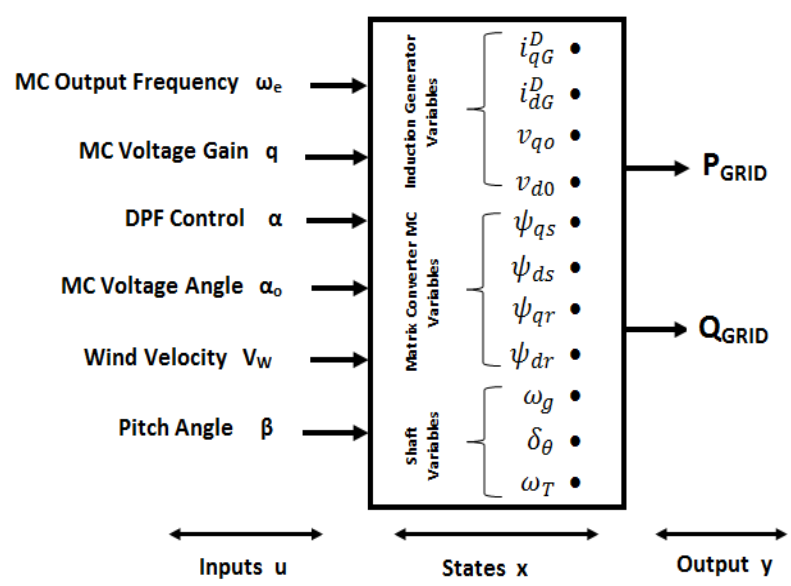

Fig 4: Inputs, state variables and outputs of the overall dynamic model of wind turbine system

\section{LINEARIZED MODEL OF THE WIND TURBINE SYSTEM}

The nonlinear state-space model of the wind turbine system contains eleven nonlinear equations. The sources of nonlinearity are the turbine torque equation, induction machine equations, and the MC equation. The small-signal model is developed by linearizing the eleven nonlinear equations around an operating point. The linearized model, is described by the following state-space equations:

$$
\begin{gathered}
\frac{d}{d t} \Delta \bar{X}=A \Delta \bar{X}+B \Delta \bar{U} \\
\Delta \bar{Y}=C \Delta \bar{X}+D \Delta \bar{U},
\end{gathered}
$$

Where,

$\Delta \bar{X}=\left[\Delta i_{q G}^{D} \Delta i_{d G}^{D} \Delta v_{q o} \Delta v_{d o} \Delta \psi_{q s} \Delta \psi_{d s} \Delta \psi_{q r} \Delta \psi_{d r} \Delta \omega_{g} \Delta(\delta \theta) \Delta \omega_{T}\right]^{\mathrm{T}}$

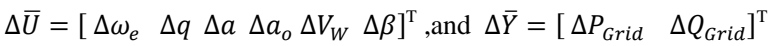


In equation (24), A, B, C, and D are the Jacobian matrices, calculated at the operating point. This linearization results in the matrices A, B, C, and D as follows:

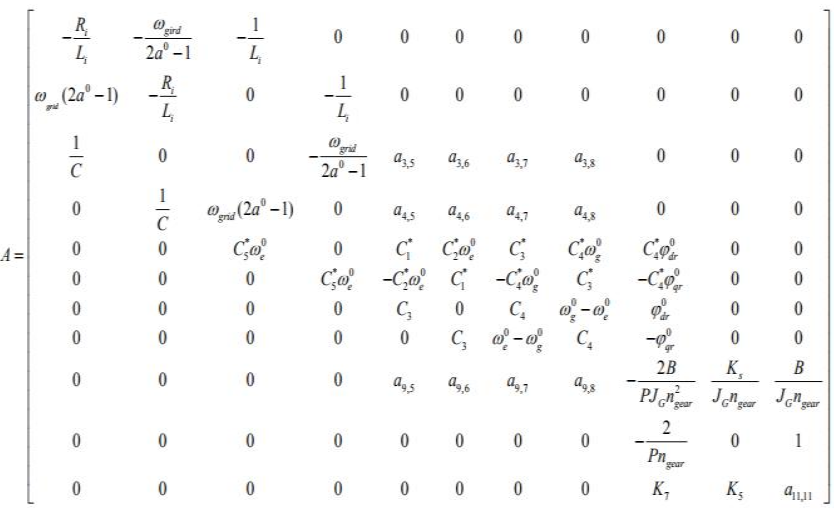

$$
\begin{aligned}
& B=\left[\begin{array}{ccccc}
\frac{V_{M} K_{V F} \cos \left(\alpha_{o}^{0}\right)}{L_{i}} & \left(\frac{2 \omega_{i} D_{d G}^{D}}{(2 a-1)^{2}}\right)^{0} & -\frac{V_{M} K_{V F}\left(\sin \left(\alpha_{o}\right) \omega_{e}\right)^{0}}{L_{i}} & 0 & 0 \\
-\frac{V_{M} K_{V F} \sin \left(\alpha_{o}^{0}\right)}{L_{i}} & 2 \omega_{g r i d}\left(i_{q G}^{D}\right)^{0} & -\frac{V_{M} K_{V F}\left(\cos \left(\alpha_{o}\right) \omega_{e}\right)^{0}}{L_{i}} & 0 & 0 \\
b_{3,1} & \frac{2 \omega_{g r d} v_{d o}^{0}}{\left(2 a^{0}-1\right)^{2}} & b_{3,3} & 0 & 0 \\
b_{4,1} & b_{4,2} & b_{4,3} & 0 & 0 \\
C_{2}^{*} \psi_{d s}^{0}+C_{5}^{*} v_{q o}^{0} & 0 & 0 & 0 & 0 \\
-C_{2}^{*} \psi_{q s}^{0}+C_{s}^{*} v_{d o}^{0} & 0 & 0 & 0 & 0 \\
-\psi_{d r}^{0} & 0 & 0 & 0 & 0 \\
\psi_{q r}^{0} & 0 & 0 & 0 & 0 \\
b_{9,1}^{0} & 0 & 0 & 0 & 0 \\
0 & 0 & 0 & 0 & 0 \\
0 & 0 & 0 & b_{11,4} & b_{11,5}
\end{array}\right]
\end{aligned}
$$

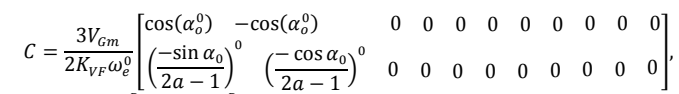

$$
\begin{aligned}
& D=\frac{3 V_{G m}}{2 K_{V F} \omega_{e}^{0}}\left[\begin{array}{ccccc}
\left(\frac{i_{G G}^{D} \cos \alpha_{0}-i_{d G}^{D} \sin \alpha_{0}}{\omega_{e}}\right)^{0} & 0 & \left(i_{q G}^{D} \sin \alpha_{0}+i_{d G}^{D} \cos \alpha_{0}\right)^{0} & 0 & 0 \\
-\left(\frac{i_{q G}^{D} \sin \alpha_{0}+i_{d G}^{D} \cos \alpha_{0}}{\omega_{e}(2 a-1)}\right)^{0} & -2\left(\frac{i_{a G}^{D} \sin \alpha_{0}+i_{d G}^{D} \cos \alpha_{0}}{(2 a-1)^{2}}\right)^{0} & \left(\frac{\cos \left(\alpha_{0}\right) i_{q_{G}}^{D}-\sin \left(\alpha_{0}\right) i_{d G}^{D}}{(2 a-1)}\right)^{0} & 0 & 0
\end{array}\right]
\end{aligned}
$$

Where,

$K_{1}^{0}=\left(\frac{V_{W}}{\omega_{T}}\right)^{0}, K_{1}^{0}=\frac{\pi}{15-0.3 \beta^{0}}\left(\left(\frac{R \omega_{T}}{V_{W}}\right)^{0}-3\right), K_{3}^{0}=K_{1}+K_{2} \beta^{0}, K_{4}^{0}=-R \frac{\pi V_{W}^{0}}{15-0.3 \beta^{0}}$

$K_{6}^{0}=V_{W}^{0}, \quad K_{7}^{0}=K_{1}^{0}\left(K_{6}^{0}\right)^{2} \frac{0.3 \pi}{\left(15-0.3 \beta^{0}\right)^{2}}\left(\frac{R}{K_{1}^{0}}-3\right)$,

$a_{3,5}=A_{7_{-} 1}\left(\left(\omega_{e} \cos ^{2}\left(\alpha_{0}\right)\right)^{0}, \quad a_{3,6}=\frac{1}{2} A_{7_{-} 1}\left(\left(\omega_{e} \sin \left(2 \alpha_{0}\right)\right)^{0}, a_{3,7}=A_{8_{-} 1}\left(\left(\omega_{e} \cos ^{2}\left(\alpha_{0}\right)\right)^{0}\right.\right.\right.$,

$a_{3,8}=\frac{1}{2} A_{8_{-} 1}\left(\omega_{e} \sin \left(2 \alpha_{0}\right)\right)^{0}, \quad a_{4,5}=\frac{1}{2} A_{7_{-} 1}\left((2 a-1)^{2} \omega_{e} \sin \left(2 \alpha_{0}\right)\right)^{0}$,

$a_{4_{-} 6}=A_{7_{-} 1}\left((2 a-1)^{2} \omega_{e} \cos ^{2}\left(\alpha_{0}\right)\right)^{0}, \quad a_{4,7}=\frac{1}{2} A_{8_{-} 1}\left((2 a-1)^{2} \omega_{e} \sin \left(2 \alpha_{0}\right)\right)^{0}$,

$a_{4_{8}}=A_{8_{1}}\left((2 a-1)^{2} \omega_{e} \cos ^{2}\left(\alpha_{0}\right)\right)^{0}$,

$a_{9,5}=\frac{-C_{6}}{J_{G}\left(\omega_{e}^{2}\right)^{0}} \psi_{d r}^{0}, a_{9,6}=\frac{C_{6}}{J_{G}\left(\omega_{e}^{2}\right)^{0}} \psi_{q r}^{0}, a_{9,7}=\frac{C_{6}}{J_{G}\left(\omega_{e}^{2}\right)^{0}} \psi_{d s}^{0}, a_{9,8}=\frac{-C_{6}}{J_{G}\left(\omega_{e}^{2}\right)^{0}} \psi_{q s}^{0}$,

$a_{11,11}=\left(-\left(K_{1}^{0}\right)^{2} K_{6}^{0} \sin \left(K_{2}^{0}\right)-K_{1}^{0} K_{4}^{0} \cos \left(K_{2}^{0}\right)\right) K_{3}^{0}-\left(K_{1}^{0}\right)^{2} K_{5}^{0} K_{6}^{0} K_{4}+K_{6}$,

$b_{3,1}=\left\{A_{7}^{*}\left[\cos ^{2}\left(\alpha_{0}\right) \varphi_{q s}+\frac{1}{2} \sin \left(2 \alpha_{0}\right) \psi_{d s}\right]+A_{8}^{*}\left[\cos ^{2}\left(\alpha_{0}\right) \psi_{q r}+\frac{1}{2} \sin \left(2 \alpha_{0}\right) \psi_{d r}\right]\right\}^{0}$,

$b_{3,3}=\left\{\omega_{e}\left\{A_{7}^{*}\left[-\sin \left(2 \alpha_{0}\right) \psi_{q s}+\cos \left(2 \alpha_{0}\right) \psi_{d s}\right]+A_{8}^{*}\left[-2 \sin \left(\alpha_{0}\right) \psi_{q r}+\cos \left(2 \alpha_{0}\right) \psi_{d r}\right]\right\}^{0}\right\}$,

$b_{4,1}=\left\{(2 a-1)^{2}\left\{A_{7}^{*}\left[\frac{1}{2} \sin \left(2 \alpha_{0}\right) \psi_{q s}+\cos ^{2}\left(\alpha_{0}\right) \psi_{d s}\right]+A_{8}^{*}\left[\frac{1}{2} \sin \left(2 \alpha_{0}\right) \psi_{q r}+\cos ^{2}\left(\alpha_{0}\right) \psi_{d r}\right]\right\}\right\}^{0}$,

$b_{4,2}=\left\{4(2 a-1) \omega_{e}\left\{A_{7}^{*}\left[\frac{1}{2} \sin \left(2 \alpha_{0}\right) \psi_{q s}+\cos ^{2}\left(\alpha_{0}\right) \psi_{d s}\right]+A_{8}^{*}\left[\frac{1}{2} \sin \left(2 \alpha_{0}\right) \psi_{q r}+\cos ^{2}\left(\alpha_{0}\right) \psi_{d r}\right]\right\}\right\}^{0}$,

$b_{4,3}=\left\{(2 a-1)^{2} \omega_{e}\left\{A_{7}^{*}\left[\cos \left(2 \alpha_{0}\right) \psi_{q s}-\sin \left(2 \alpha_{0}\right) \psi_{d s}\right]+A_{8}^{*}\left[\cos \left(2 \alpha_{0}\right) \psi_{q r}-\cos \left(2 \alpha_{0}\right) \psi_{d r}\right]\right\}\right\}^{0}$,

$b_{9,1}=\frac{2 C_{6}}{\left(\omega_{e}^{3}\right)^{0}}\left(\psi_{d r}^{0} \psi_{q s}^{0}-\psi_{q r}^{0} \psi_{d s}^{0}\right)$,

$b_{11,4}=\left\{\left(3 K_{1}^{0} K_{6}^{0} \sin \left(K_{2}^{0}\right)+K_{4}^{0} \cos \left(K_{2}^{0}\right)\right) K_{3}^{0}+2 K_{5}^{0} K_{6}^{0} K_{3}+3 K_{1}^{0} K_{5}^{0} K_{6}^{0} K_{4}\right\}$

$b_{11,5}=\left\{K_{7}^{0} K_{3}^{0} \cos \left(K_{2}^{0}\right)+K_{1}^{0}\left(K_{6}^{0}\right)^{2} K_{2} \sin \left(K_{2}^{0}\right)+\left(K_{6}^{0}\right)^{2} K_{3}+K_{1}^{0}\left(K_{6}^{0}\right)^{2} K_{4}\right\}$

\section{OUTPUT EQUATIONS OF THE SMALL-SIGNAL MODEL}

The output of small-signal model contains the grid real and reactive powers, i.e., $\Delta \mathrm{P}_{\text {Grid }}$ and $\Delta \mathrm{Q}_{\text {Grid }}$ that can be derived based on the nonlinear equations (22) and (23), as follows:
$\Delta P_{\text {Grid }}=\frac{3 V_{G m}}{2 K_{V F} \omega_{e}^{0}}\left[\cos \left(\alpha_{o}^{0}\right) \Delta i_{q G}^{D}-\sin \left(\alpha_{o}^{0}\right) \Delta i_{d G}^{D}-\left(\sin \left(\alpha_{o}\right) i_{q G}^{D}+\cos \left(\alpha_{o}\right) i_{d G}^{D}\right)^{0} \Delta \alpha_{o}\right.$

$$
\left.-\frac{1}{\omega_{e}^{0}}\left(\cos \left(\alpha_{o}\right) i_{q G}^{D}-\sin \left(\alpha_{o}\right) i_{d G}^{D}\right)^{0} \Delta \omega_{o}\right]
$$

$$
\begin{gathered}
Q_{\text {Grid }}=-\frac{3 V_{G m}}{2 K_{V F}}\left(\frac{1}{(2 a-1) \omega_{e}}\right)^{0}\left[\sin \left(\alpha_{o}^{0}\right) \Delta i_{q G}^{D}+\cos \left(\alpha_{o}^{0}\right) \Delta i_{d G}^{D}+\left(\cos \left(\alpha_{o}\right) i_{q G}^{D}\right.\right. \\
\left.-\sin \left(\alpha_{o}\right) i_{d G}^{D}\right)^{0} \Delta \alpha_{o}+\left(\sin \left(\alpha_{o}\right) i_{q G}^{D}\right. \\
\left.+\cos \left(\alpha_{o}\right) i_{d G}^{D}\right)^{0}\left(\frac{-2}{\left(2 a^{0}-1\right)} \Delta a-\frac{1}{\omega_{e}^{0}} \Delta \omega_{e}\right]
\end{gathered}
$$

\section{FEEDBACK QUADRATIC FUNCTION CONTROLLER}

The theory of optimal control is concerned with operating a dynamic system at minimum cost. The case where the system dynamics are described by a set of linear differential equations and the cost is described by a quadratic function is called the $\mathrm{QR}$ problem. One of the main results in the theory is that the solution is provided by the linear - quadratic regulator, a feedback controller whose shown in Figure 5.

The QR algorithm is essentially an automated way of finding an appropriate state - feedback controller. As such, it is not uncommon for control engineers to prefer alternative methods, like full state feedback, also known as pole placement, in which there is a clearer relationship between controller parameters and controller behavior. Difficulty in finding the right weighting factors limits the application of the QR based controller synthesis.

The schematic $_{1}$ of this type of control system is shown below where $\mathbf{K}$ is a matrix of control gains. Note that here the feedback for all of the system's states will be done, rather than using the system's outputs for feedback. [10]

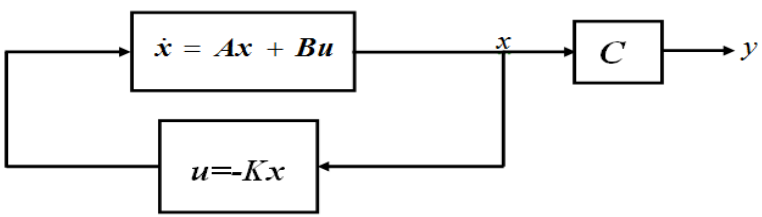

Fig 5: Normalized Feedback Quadratic Structure

Design an $\mathrm{QR}$ control law $u=-K x$ which solves the following Problem,

$$
\begin{aligned}
& \dot{x}=A x+B u \\
& \left.J_{(x, u, Q, R)}=\int_{0}^{\infty}\left(x^{T} Q x+R u^{2}\right) d t, Q \geq 0, R\right\rangle 0 \\
& \text { i.e., compute } \\
& A^{T} P+P A-P B R^{-1} B^{T} P+Q=0, \\
& P>0, \quad K=R^{-1} B^{T} P
\end{aligned}
$$

\section{RESULTS}

To verify the stability it is important to check the eigenvalues of the linearized system. When the real parts of all eigenvalues of the linearized system are negative, the nonlinear system is locally stable around the steady-state operating point. The eigenvalues of the small-signal model linearized around the operating point are shown in Table 1. The real parts of all eigenvalues are negative; therefore, the linearized small signal model is asymptotically stable at the steady-state operating point. 


\section{Table 1 Eigen Values}

$-12.205 \pm 32.232 \mathrm{i}$
-25.237
$-28.126 \pm 140.2 \mathrm{i}$
$-49.646 \pm 32400 \mathrm{i}$
$-49.764 \pm 31574 \mathrm{i}$
$-50.91 \pm 372.8 \mathrm{i}$

Next, to calculate the maximal and minimal singular values at the (arbitrary) frequency $\omega=10 \mathrm{rad} / \mathrm{s}$ for the two studied cases, namely the closed loop feedback system with unity controller and the feedback linear quadratic regulator controller. The plot shows us that the maximal and minimal singular values are very close to each other at the crossover frequency when using feedback regulator controller, as shown in Figure 6.

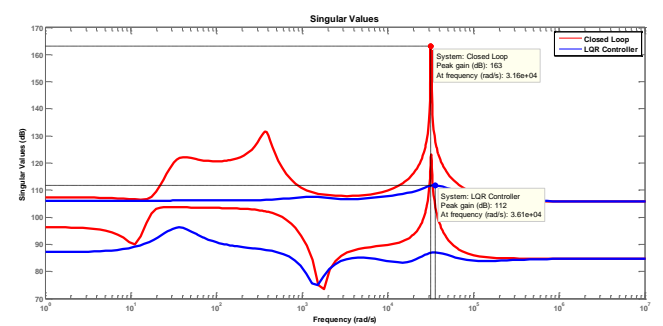

Fig 6: Singular Values

That tells the designer for the good parameters choice for the proposed linear quadratic regulator controller, and thats because the controlled system shows an 'almost SISO' behavior at the crossover frequency. Figures (7-15) shows the active and reactive power changes of the wind turbine system to changes in output frequency, displacement power factor, voltage angle, wind velocity and pitch angle respectively.

Table 2 and Table 3 shows the comparison between the settling time for the application of the unity feedback controller and Feedback regulator controller.

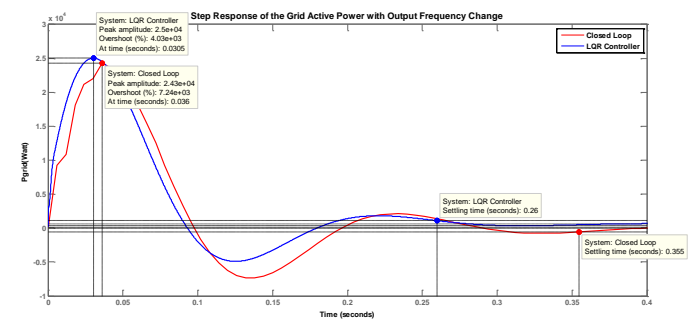

Fig 7: Step Response of the Grid Active Power with Output Frequency Change

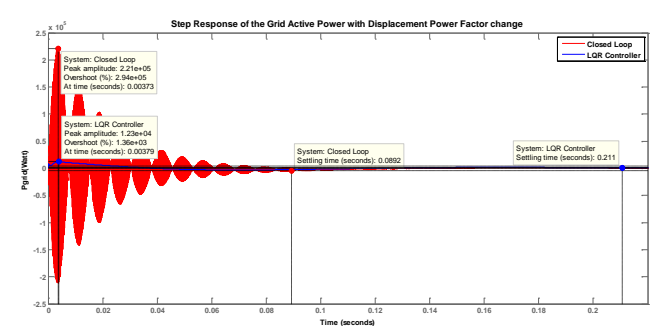

Fig 8: Step Response of the Grid Active Power with Displacement Power Factor Change

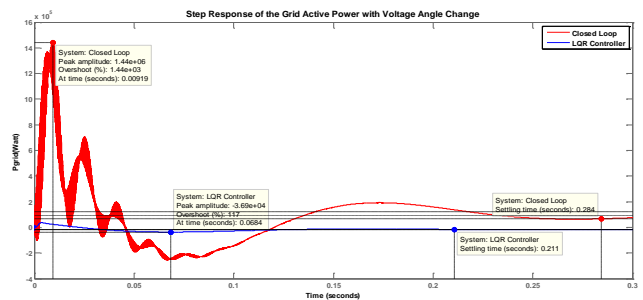

Fig 9: Step Response of the Grid Active Power with Voltage Angle Change

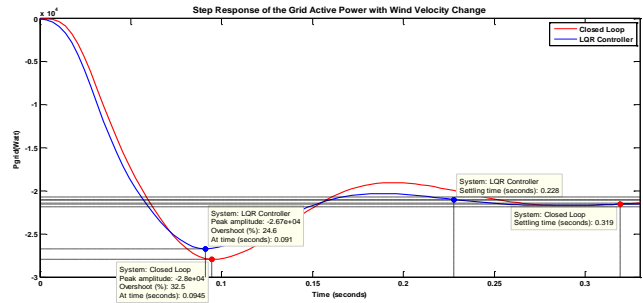

Fig 10: Step Response of the Grid Active Power with Wind Velocity Change

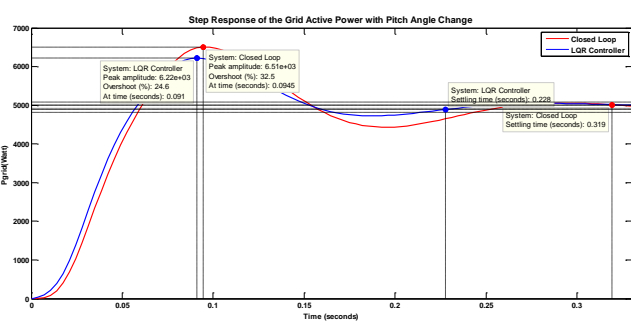

Fig 11: Step Response of the Grid Active Power with Pitch Angle Change

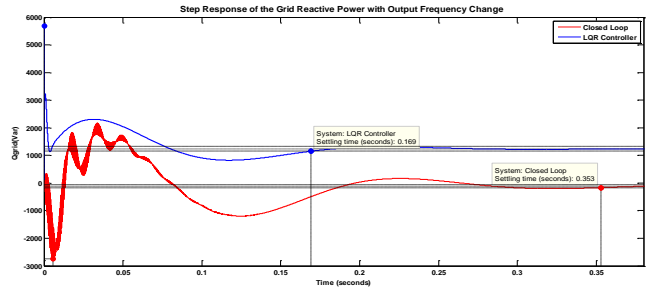

Fig 12: Step Response of the Grid Reactive Power with Output Frequency Change

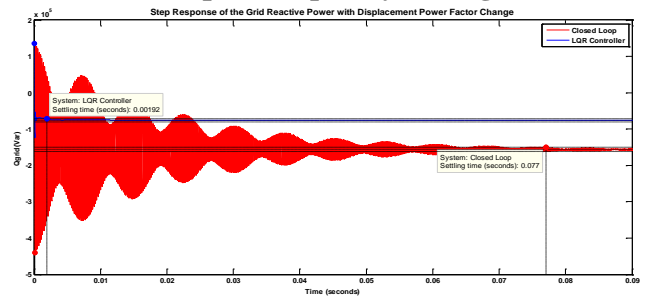

Fig 13: Step Response of the Grid Reactive Power with Displacement Power Factor Change

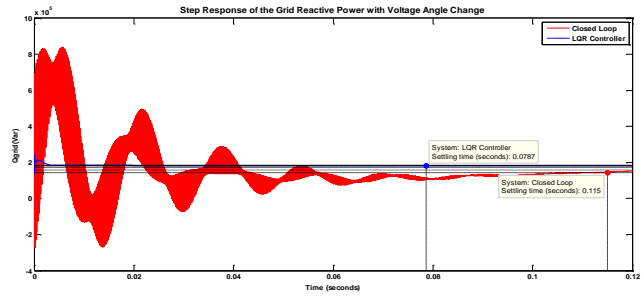

Fig 14: Step Response of the Grid Reactive Power with Voltage Angle Change 


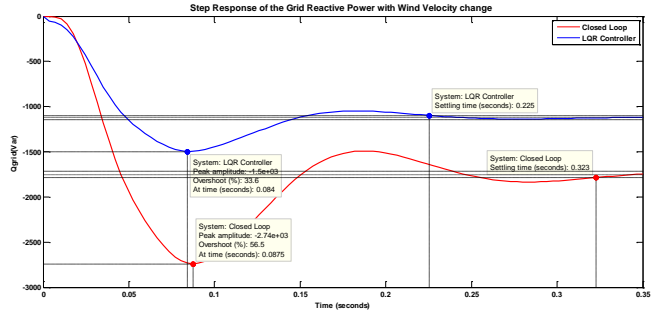

Fig 15: Step Response of the Grid Reactive Power with Wind Velocity Change

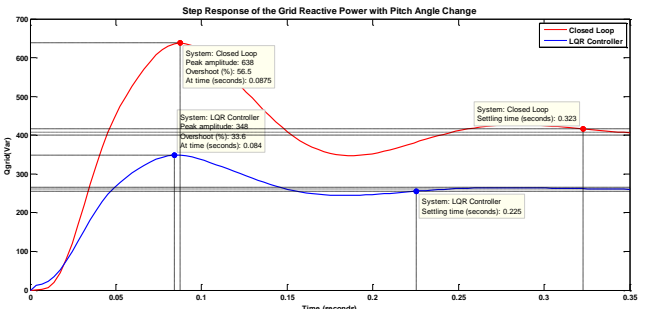

Fig 16: Step Response of the Grid Reactive Power with Pitch Angle Change

Table.2 Grid Active Power $\left(P_{\text {Grid }}\right)$ Settling Time Response

\begin{tabular}{|c|c|c|}
\hline Change & $\begin{array}{l}\text { Settling Time } \\
\text { for Closed } \\
\text { Loop, sec }\end{array}$ & $\begin{array}{l}\text { Settling Time } \\
\text { for Regulator } \\
\text { Feedback, sec }\end{array}$ \\
\hline Output Frequency & 0.355 & 0.26 \\
\hline Displacement Power Factor & 0.0892 & 0.211 \\
\hline Voltage Angle & 0.284 & 0.211 \\
\hline Wind Velocity & 0.319 & 0.228 \\
\hline Pitch Angle & 0.319 & 0.228 \\
\hline \multicolumn{2}{|c}{}
\end{tabular}

Table.3 Grid Reactive Power $\left(Q_{\text {Grid }}\right)$ Settling Time Response

\begin{tabular}{|c|c|c|}
\hline \multicolumn{3}{|c|}{ Response } \\
\hline & $\begin{array}{l}\text { Settling Time } \\
\text { for Closed } \\
\text { Loop, sec }\end{array}$ & $\begin{array}{l}\text { Settling Time } \\
\text { for Regulator } \\
\text { Feedback, sec }\end{array}$ \\
\hline Output Frequency & 0.353 & 0.169 \\
\hline Displacement Power Factor & 0.077 & 0.00192 \\
\hline Voltage Angle & 0.115 & 0.0787 \\
\hline Wind Velocity & 0.323 & 0.225 \\
\hline Pitch Angle & 0.323 & 0.225 \\
\hline
\end{tabular}

\section{CONCLUSION}

In this paper, the investigation of the apparent power (MVA) profile resulting from connecting the wind energy system on the power grid, in which the effect of changing number of inputs, namely output frequency, displacement power factor, voltage angle, wind velocity and pitch angle respectively, has been studied.

As shown in figures from (7-16), Table 2 and Table 3, that there is an enhancement in the step response profiles for the MVA profile (i.e. the MW and MVAR) resulting from the change in the pre mentioned inputs, when using feedback regulator controller.

\section{Parameters of the system under study[11]}

\section{Induction Generator}

$500[\mathrm{hp}], \quad 2.3[\mathrm{kV}], \quad 1773[\mathrm{rpm}], \quad \mathrm{T}_{\mathrm{B}}=1.98 \times 10^{3} \quad$ [N.m],
$\mathrm{I}_{\mathrm{B}(\mathrm{abc})}=93.6[\mathrm{~A}], \mathrm{r}_{\mathrm{s}}=0.262, \mathrm{r}_{\mathrm{r}}=0.187[\Omega], \mathrm{X}_{\mathrm{ls}}=1.206, \mathrm{X}_{\mathrm{lr}}=1.206$, $\mathrm{X}_{\mathrm{M}}=54.02 \quad[\Omega], \quad \mathrm{J}=11.06\left[\mathrm{Kg} . \mathrm{m}^{2}\right], \quad \mathrm{P}=4$ [Poles $]$ $\mathrm{P}_{\text {mech } \_ \text {loss }}=1 \% \mathrm{P}_{\text {rated }}$

\section{Wind Turbine System}

$\mathrm{J}_{\mathrm{T}}=100\left[\mathrm{~kg} \cdot \mathrm{m}^{2}\right], \mathrm{K}_{\mathrm{s}}=2 \times 10^{6}[\mathrm{Nm} / \mathrm{rad}], \mathrm{B}=5 \times 10^{3}[\mathrm{Nm} / \mathrm{rad} / \mathrm{s}]$ $\mathrm{n}_{\text {gear }}=20, \rho_{\text {air }}=1.25\left[\mathrm{~kg} / \mathrm{m}^{3}\right], \mathrm{R}=10[\mathrm{~m}]$

\section{Matrix Converter}

$\mathrm{R}_{\mathrm{i}}=\mathrm{R}_{\mathrm{o}}=0.1[\Omega], \mathrm{L}_{\mathrm{i}}=\mathrm{L}_{\mathrm{o}}=1[\mathrm{mH}], \mathrm{C}=0.1[\mathrm{mF}], 0 \leq \mathrm{q} \leq 0.87,0 \leq \mathrm{a} \leq 1$

Grid(Infinite Bus)

$\mathrm{V}_{\mathrm{G}}=4[\mathrm{kV}], \mathrm{f}_{\mathrm{G}}=60[\mathrm{~Hz}]$

\section{REFERENCES}

[1] Z. Boudjema, A. Meroufel and Y. Djerriri, "Nonlinear control of a doubly fed induction generator for wind energy conversion", Carpathian Journal of Electronic and Computer Engineering, 6/1, 28-35, 2013.

[2] Dinh-Chung Phan and Shigeru Yamamoto," Maximum Energy Output of a DFIG Wind Turbine Using an Improved MPPT-Curve Method", Energies, 8, pp. 11718-11736, 2015.

[3] Carlos E. Ugalde-Loo and Janaka B. Ekanayake, " StateSpace Modelling of Variable-Speed Wind Turbines: A Systematic Approach", IEEE ICSET 2010 6-9 Dec 2010, Kandy, Sri Lanka.

[4] Istvan Erlich, Fekadu Shewarega and Oliver Scheufeld, " Modeling Wind Turbines in the Simulation of Power System Dynamics", Scientific Journal of Riga Technical University, Volume 27, pp.41-47, 2010.

[5] Carlos E. Ugalde-Loo , Janaka B. Ekanayake and Nicholas Jenkins, "State-Space Modelling of VariableSpeed Wind Turbines for Power System Studies ", IEEE Transactions on Industry Applications, January 2013.

[6] Amina Bouzekri , Tayeb Allaoui, Mouloud Denai and Youcef Mihoub, "Artificial Intelligence-Based Fault Tolerant Control Strategy in Wind Turbine Systems", International Journal of Renewable Energy Research A. Bouzekri, Vol.7, No.2, 2017.

[7] Yi Zhang, Xiangjie Liu, and Bin Qu"Distributed Model Predictive Load Frequency Control of Multi-area Power System with DFIGs", IEEE/CAA Journal of Automatica Sinica, Vol. 4, No. 1, January 2017

[8] S. Masoud Barakati, " Modeling and Controller Design of a Wind Energy Conversion System Including a Matrix Converter", Ph.D. thesis, Waterloo, Ontario, Canada, 2008

[9] Bijaya Pokharel, "Modeling, Control and Analysis of a Doubly Fed Induction Generator Based Wind Turbine System with Voltage Regulation", M.Sc. Thesis at Tennessee Technological University, December 2011.

[10] F.L.Lewis: Control System Design Project; lecture 11, 1999.

[11] P. C. Krause, O Wasynczuk, S. D. Sudhoff, Analysis of electric machinery, IEEE Press, 1994. 